\title{
Expressão artística e linguagem no audiovisual: A Conversão de Vinicius de Moraes
}

Lucas Bezerra Facó

Introdução.

O presente ensaio busca pensar as reconfigurações da experiência contemporâneas ocasionadas pelo surgimento e desenvolvimento da esfera audiovisual. Dito de outra forma, vamos atentar para a maneira como o audiovisual tornou-se constituinte das subjetividades contemporâneas, ocasionando lugares de subjetivação e experiências não antes possíveis. O problema não será, contudo, atacado de maneira abstrata; tem-se em mente uma historicidade bastante específica: o entrecruzamento da esfera tecnológica audiovisual com a produção cultural e artística. De maneira mais precisa, busquei compreender as mudanças pelas quais passou o corpo do artista mediante a incorporação, aos circuitos das artes, do aparato de produção e difusão audiovisual.

Esta mudança concerne também ao público consumidor das produções simbólicas grafadas sob o signo da arte. Adiantando o argumento, quero dizer que, por meio da difusão sem precedentes de sons e imagens dos artistas, e por meio do lugar privilegiado que as linguagens calcadas na transmissão de sons e imagens assumem nos processos comunicativos humanos no decorrer do século $\mathrm{XX}$, a integralidade do corpo do artista torna-se significante de práticas culturais - em outras palavras, seu corpo torna-se um bem simbólico ao lado e em relação com sua produção artística na medida em que os novos meios se inscrevem neste corpo. A contrapartida deste processo em relação ao público é que o artista, sob um ponto de vista bastante mais integral, torna-se modelo para práticas dotadas de sentido. Sentido esse que, devido ao extravasamento da arte de sua esfera própria de experiência, não se refere mais à arte ou à vida, mas a uma conjunção de ambas.

\section{Linguagens audiovisuais?}

Para pensar esses aspectos parto da perspectiva de Walter Benjamin a respeito do cinema, no seu clássico ensaio $A$ obra de arte na era de sua reprodutibilidade técnica. Os meandros do argumento deste autor não são nosso principal ponto de interesse. O que busco reter em sua argumentação é sua postura irredutível de não refletir os processos de tecnização da vida em separado da historicidade de que fazem parte. Isto surge em sua argumentação de maneira muito viva 
o valor de culto. Este último é precisamente o caráter religioso que a arte burguesa secularizada conserva. A presença, na apreciação da obra, de um algo ausente e distante. A história da arte burguesa seria, então, uma história de tensão crescente. Por um lado, o valor de culto das obras de arte cresce na medida da constante atualização de seu valor e originalidade ao longo do tempo. A referência ao cânone que ratifica o cânone. Por outro lado, os progressivos avanços dos meios de reprodução técnica dessas obras de arte crescentemente ameaçam seu estatuto artístico, isto é, ameaçam pôr a nu a negação de sua materialidade de labor técnico humano, negação essa constitutiva de seu caráter aurático. O cinema, por meio de suas virtudes técnicas, romperia essa tensão em favor do valor de exposição, da imanência de uma arte que, em seu esquema, é puro sensório. E em favor de uma nova forma de contato com a cultura. Esta via de seu argumento nos permite pensar outras estéticas calcadas em uma relação diferente do corpo com os sentidos.

A segunda direção em que Benjamin leva seu argumento diz respeito às transformações da sensibilidade humana possibilitadas pelo cinema. O influxo de estímulos em que consiste o cinema não passou despercebido pelo autor. A Benjamin interessava a possibilidade de que o cinema agisse como uma nova forma de conhecimento sobre realidade humana na sua relação com o espaço, isto ao proporcionar ao aparelho sensório a experiência quase-tátil da câmera.

Vemos ainda que essas duas ordens de preocupações compõem um modelo sociológico único, calcado essencialmente na 
Dentre as várias possibilidades analíticas que se perdem com transformações amplas que a reprodução técnica de imagens e sons impõe à vida humana, modelo esse que opera por meio da triangulação entre um corpo humano histórico, os desenvolvimentos da técnica autonomizada e a trajetória da esfera de produção de sentidos depositária do monopólio do sagrado secularizado - a arte.

A este modelo benjaminiano, cabe acrescentar um elemento importante, que detalha esta triangulação e permite uma compreensão mais ampla do lugar do audiovisual na experiência: a linguagem. $\mathrm{Ou}$ melhor, as linguagens. Tomar o audiovisual como constituinte de linguagens contemporâneas nos possibilita entendê-lo como uma forma de conhecimento e de experiência, isto é, enriquece a proposta inicial de dar conta de como ele atua na formação de estruturas de ação e estruturas cognitivas. Com isso podemos ultrapassar vários dos problemas a respeito da relação entre audiovisual e experiência que se colocam, geralmente, no conceito de influência. Esse conceito, bastante vago, privilegia, direta ou indiretamente, o conteúdo daquilo que é exposto em detrimento da forma - e do meio -, tratando este conteúdo como um discurso que se introduz subliminarmente pelas costas da nossa consciência - ou como uma norma opressora que cega nossa visão ante a realidade massiva da comunicação. Essas duas perspectivas tem em comum a antecedência de um sujeito constituído em sua integridade em relação ao contato com o audiovisual. Em outras palavras, negam a este último qualquer papel constitutivo nas sensibilidades e subjetividades contemporâneas ${ }^{2}$. essa enésima reificação do sujeito, uma delas diz respeito à apreensão dos bens audiovisuais enquanto dotados de uma espessura, de uma opacidade (ou um brilho) própria.

Nem reflexo nem transparência de uma realidade decalcada em imagens e sons, vamos tomar o audiovisual como constituinte de linguagens e, portanto, operações de pensamento em seus próprios termos e que merecem sua autonomia em relação à linguagem num sentido restrito ${ }^{3}$, assim como as experiências comunicativas a que dão origem merecem uma apreensão fora do registro verdadeiro-falso em que comumente se inserem os bens audiovisuais. Não se trata de um reclame pela "autonomia da arte" de representar o que quiser, a despeito de uma contrapartida "real" do representado. Este breve argumento situa-se no âmbito dos olhares acadêmicos jogados sobre a experiência dos modernos meios de produção e comunicação. Mas qual o "defeito" desses olhares?

Trata-se, sim, de aspectos incontornáveis da experiência deixados de fora da reflexão em nome de preceitos epistemológicos cujas críticas não nos cabem resgatar aqui - limitados. Estas limitações, se nos apoiarmos em Luiz Costa Lima (1980), remontam ao estatuto que a duplicação pela linguagem assumiu a partir da virada socrática no pensamento grego. Para este autor, é nesse ponto da tradição ocidental que o duplo, a imitação, ou a mimesis, entendida como duplicação simbólica da experiência, foi posta sob a desconfiança da falsidade. Enquanto um fato sociológico, o autor busca caracterizar esse 
situação do sociólogo analisando o mundo social como alguém que contempla um quadro é recorrente nos debates epistemológicos da disciplina. De maneira excessivamente esquemática, podemos dizer que a afirmação de um distanciamento reflexivo em relação ao seu objeto de estudo cumpriu, inicialmente, um papel importante na institucionalização da sociologia enquanto uma disciplina acadêmica e como uma promessa de um conhecimento superior sobre o mundo - e o destino - dos seres humanos. Esta afirmação originária deu ensejo a dois tipos de discussão não necessariamente opostos nem complementares: que condições o observador do mundo social deve cumprir para garantir a integridade do conhecimento que produz e qual a natureza do social ${ }^{4}$ que - supostamente - garante a unidade da sociologia enquanto disciplina. A partir dos anos de 1970, esses dois eixos de questionamentos conduziram a um mesmo volume de críticas - com desfechos positivos ou negativos, a depender de outras orientações do autor ou da autora - endereçadas ao privilégio das ciências sociais na produção de enunciados sobre o mundo social. Por um lado, investigar as condições de possibilidade da apreensão distanciada do mundo social conduziu à historicização e ao estudo da inserção mundana das instituições que formam sociólogos - e que são por eles sustentadas -; por outro lado, investigar qual a natureza do objeto de estudo dos cientistas sociais conduziu a disciplina, por meio de uma desessencialização desse objeto, a questionar em que medida a representação que os seus praticantes fazem do mundo social é devedora do espaço social em que é produzida - ou seja, as 
responde por uma historicidade pela qual, finalmente, se reinsere a materialidade técnica do circuito audiovisual.

Para sintetizar os pontos levantados aqui, vamos nos filiar à proposta epistemológica de Hans Ulrich Gumbrecht, em seu livro Produção de Presença. A escolha deste autor se dá por uma série de afinidades que irão se esclarecer ao longo da apresentação, mas podemos adiantar alguns pontos:

1. A ressignificação do termo "presença": não mais presença a si de uma consciência, mas presença de corpos uns aos outros.

2. Sua insistência nestes efeitos de presença que as formas materiais da comunicação produzem sobre a experiência humana.

3. A reelaboração dos conceitos de signo e de comunicação para além da separação entre uma materialidade e uma espiritualidade irreconciliáveis

4. Sua tentativa de objetivar um estado de coisas nas realidade, a despeito de sua remissão a um empírico existente ou observável. Isto porque a experiência humana - tomando-nos aqui enquanto seres sócio-psico-biológicos - é irrevogavelmente mediada pelo simbólico e, inversamente, o simbólico é mediado pela experiência no sentido em que não é senão a experiência humana traduzida em linguagens diversas.

Para tomarmos o audiovisual enquanto constitutivo de linguagens, devemos, ainda, alargar tanto o atual conceito de linguagem como sua relação com a formação de estruturas cognitivas e de ação. Retirando estas últimas de sua clausura consagrada pela fenomenologia, buscou-se pensá-las na sua imensa plasticidade, que dades em que importantes aspectos da experiência são perdidos.

5. Buscar operacionalizar todos esses pontos, que não são propriamente "seus", em instrumentos de análise.

Vejamos como tudo isso se configura em sua proposta. Podemos partir do momento inicial em que o autor declara suas intenções: "Este livro assume o compromisso de lutar contra a tendência da cultura contemporânea de abandonar, e até esquecer, a possibilidade de uma relação com o mundo fundada na presença" (GUMBRECHT, 2010, p.15). Que Gumbrecht tem em mente uma luta, 
de coisas" (GUMBRECHT, 2010,p.146). O parentesco com a proposta acima de tudo, epistemológica está expressamente indicado no livro, mas vale à pena buscar, ainda no texto, indicações mais precisas a esse respeito, pois uma conclusão, importante para este ensaio, deriva deste ponto. Podemos dizer, de antemão, que o autor se alterna entre dois sujeitos de enunciação, que podemos chamar o humano e o humanista. Em certos momentos, a posição que se delineia em suas proposições é a de um ser humano pertencente a uma configuração histórica determinada, em que a produção de sentido sobre o mundo é a forma de relação prevalecente enquanto prática organizadora e produtora da vida social. Nestes momentos, o autor aponta para aspectos comuns da experiência contemporânea de uma "cultura de sentido":

\begin{abstract}
Tipologicamente, a dimensão de sentido é predominante nos mundos cartesianos, em mundos para os quais a consciência (ou seja, o conhecimento das alternativas) constitui o cerne da autorreferência humana. E não desejamos precisamente a presença não é o nosso desejo de tangibilidade tão intenso, por ser o nosso ambiente cotidiano tão quase insuperadamente centrado na consciência (GUMBRECHT, 2010, p.135 - itálicos meus).
\end{abstract}

Aqui o "nós" estende sua rede a todos aqueles que perderam, de alguma forma, o contato com as coisas do mundo, com a dimensão espacial da existência, que buscam, mesmo que inconscientemente, "recuperar um vislumbre do que podem ser "as coisas do mundo"" (GUMBRECHT, 2010, p.147). A este nós "ampliado", o autor endereça sua proposta de uma experiência estética que "nos devolva pelo menos a sensação de estarmos-no-mundo, no sentido de fazermos parte de um mundo físico benjaminiana é claro, pois se trata também de uma tentativa de apreensão do mundo que não parte de uma cisão entre um sujeito doador de sentido e um mundo material espiritualmente inerte.

Em outros momentos, esta posição é a de um pesquisador das humanidades, pertencente a certa configuração epistemológica e institucional marcada, em última instância, por um desejo de diferenciação em relação à metafísica ${ }^{6}$. Sobre os congressos a respeito das "Materialidades da Comunicação", que marcaram sua "juventude intelectual", o autor escreve:

Tínhamos a sensação enérgica e inebriante de fazer parte de e contribuir para uma alteração profunda, e só com o distanciamento das nossas retrospectivas particulares é que começamos a vislumbrar múltiplas afinidades em nosso ambiente intelectual que explicavam, pelo menos em parte, a nossa escolha de tema e a contagiante exaltação que produzira (GUMBRECHT, 2010, p.29).

Ao tentar encontrar um modo de definir essas "materialidades da comunicação" e estabelecer quais os instrumentos mais adequados para analisá-las, fomos obrigados a pensar nas Humanidades, tal como existiam (e anda hoje, na maioria dos casos, existem), como uma tradição epistemológica que, ao longo de mais de um século, nos mantivera margem de tudo que não podia ser descrito como, nem transformado numa, configuração de sentido (GUMBRECHT, 2010, p.120)

Neste compasso, o autor precisa o escopo de sua luta: 
são os complexos de sentido, independentemente da materialidade a

...este livro propõe que um certo movimento "teórico" poderá re-dinamizar nossas relações com todo tipo de artefatos culturais e até mesmo permitir que nos conectemos com alguns fenômenos da cultura atual que parecem fora do alcance das humanidades. (GUMBRECHT, 2010, p.21) diferente.

${ }^{8}$ Segundo a hierarquia que vigora nesta região, e a partir da qual esta região vigora no mundo.

Mesmo que este sentido seja

historicamente balizado.

partir da qual estes complexos puderam emergir.

Esta delimitação feita por Gumbrecht é bastante sofisticada, pois o autor não incorre na prática, academicamente dominante, de estabelecer o sentido do mundo ${ }^{9}$ como marcado pelos efeitos de sentido; tampouco faz de sua exposição uma denúncia - que frequentemente se quer revolucionária - de um divórcio total entre as práticas acadêmicas de interpretação e o "mundo real". O autor quer, sim, reinscrever certas práticas intelectuais - de interpretação - na esteira de uma tradição situada em uma determinada região da cultura ocidental - as artes e as humanidades - que se pretende uma forma de consciência meta-histórica desta cultura, isto é, numa porção da cultura onde se elabora a "semântica auto-descritiva" dessa mesma cultura:

Todas as culturas e objetos culturais podem ser analisados como configurações de efeitos de sentido e de efeitos de presença, embora suas diferentes semânticas autodescritivas acentuem com frequência apenas um ou outro aspecto (GUMBRECHT, 2010, p.41).

O mundo, enquanto um controle e um horizonte da atividade hermenêutica, começa a perder sua antecedência; sujeito e objeto passam a ser, em sua argumentação, termos da semântica autodescritiva ocidental, que recalca os fenômenos de presença. Assim, outro mundo desponta aos olhares dos acadêmicos do círculo de congressos relatado por Gumbrecht, o mundo dos efeitos de presença; mas iluminar este 
${ }^{10}$ Já que simplesmente abolir e eliminar esta oposição dos textos e do pensamento é uma ingenuidade tão grande quanto à pretensão de superá-la.

${ }_{11}$ A própria expressão "efeitos de sentido" já é um passo em direção à proposta do autor, pois assume, de maneira implícita ou explícita, que o sentido se produz em uma estrutura excitável e, portanto, contingente: o sentido é uma contingência, sua idealidade e igualdade a si são teoricamente - a repetição indefinida dessa contingência, de suas condições de possibilidade históricas. A proximidade desta proposta com a de Jacques Derrida, por exemplo, em A Voz e o Fenômeno, evidente.

${ }^{12}$ Este último campo de análises surge quando nos demovemos do preconceito hierárquico que submete as diversas formas de materialidade ao conteúdo ideal da comunicação, soterrando dessa forma a questão das relações possíveis entre uma e outra instância.

Enquanto conceito-chave dessa configuração intelectual.

14 Contingência entendida enquanto aquilo que é dispensável.

${ }^{15}$ Podemos nos perguntar, ao menos no que diz respeito às humanidades, se existe uma intervenção epistemológica que não seja, ao mesmo tempo, uma intervenção nas práticas intelectuais e, partir daí, uma transformação maior ou menor da inserção dos intelectuais no seu mundo. Este parece ser precisamente caminho pretendido por Gumbrecht.

${ }^{16} \mathrm{Na}$ sociologia especificamente, desde, pelo menos, Max Weber nós sabemos

Dossiê Literatura e Memória

Arquivos do CMD, Volume 3 N.2. Ago/Dez 2015 domínio não foi suficiente, pois tratava-se de um domínio desconhecido - esquecido, como prefere o autor:

Já não acreditávamos que um complexo de sentido pudesse estar separado de sua medialidade... Mas ainda não sabíamos muito bem como lidar com essa interface de sentido e materialidade... nós ainda não estávamos conceitualmente preparados para tomá-la de modos que não fossem apenas metafóricos (GUMBRECHT, 2010, p.32-3)

É na oposição entre sentido e presença que se firma este desconhecimento; sendo assim, Gumbrecht argumenta em favor de uma complexificação das relações concebíveis entre essas duas instâncias ${ }^{10}$ - não mais oposição, mas ambivalência, alternância, interferência, etc. Se a materialidade da comunicação é tudo aquilo que produz sentido, mas que não é sentido, e a emergência dos complexos de sentido não pode mais ser separada de sua medialidade, então toda produção de sentido se faz ao redor, na vizinhança inseparável das "coisas do mundo". A partir dessa decisão, todo o campo de análise dos efeitos sentido $^{12}$ seria acompanhado por outros dois, espécies de ocultos coextensivos dos efeitos de sentido: da análise dos efeitos de presença, bem como das alterações estatutárias que um campo impõe ao outro na história humana ${ }^{13}$ :

Pode ser mais ou menos banal observar que qualquer forma de comunicação implica tal produção de presença; que qualquer forma de comunicação, com seus elementos materiais, "tocará" os corpos das pessoas que estão em deixa de ser verdade que isso havia sido obliterado (ou progressivamente esquecido) pelo edifício teórico do Ocidente desde que o cogito cartesiano fez a ontologia da existência humana depender exclusivamente dos movimentos do pensamento humano (GUMBRECHT, 2010, p.39).

Gumbrecht opõe o imponente edifício teórico do Ocidente, a virada cartesiana e outras figuras de grandeza à banalidade de um gesto, um "toque" da voz; o mundo ${ }^{14}$ às coisas do mundo (GUMBRECHT, 2010, p.13). É um argumento em favor da dispersão de efeitos que, na medida em que promove uma revalorização da contingência ${ }^{15}$ na apreensão da experiência, deixa o plano estritamente epistemológico ${ }^{16}$ em direção ao plano vivencial dos intelectuais ${ }^{16}$. Toda a estrutura de relato deste instigante capítulo reforça esse ponto de vista, e é nesse sentido que o autor finaliza sua proposta de livro. Antes mesmo de sua intuição lhe propor o tema da presença, Gumbrecht se sente marcado por um desejo de presença:

Em um nível primário, os efeitos da presença tem sido tão completamente banidos que agora regressam sob a forma de um intenso desejo de presença - reforçado ou até iniciado por muitos dos nossos meios de comunicação contemporâneos. Nosso fascínio pela presença - ou seja, a tese final deste livro - baseia-se num desejo de presença que, no contexto da contemporaneidade, só pode ser satisfeito em condições de fragmentação temporal extrema (GUMBRECHT, 2010, p.42)

Este apelo ao desejo de presença parece central para sua argumentação É, enfim, por meio deste elemento que o autor estabelece uma comunidade de experiência entre o humano e o humanista: 
revolveria o mesmo drama - sua incapacidade de tocar as coisas -,

Minha contribuição marginal [com o livro] (mas, espero, não completamente trivial) é muito mais de dizer que essa dimensão cartesiana não cobre (nunca deveria cobrir) toda a complexidade da nossa existência, embora sejamos levados a acreditar que o faz, talvez com pressão mais avassaladora do que alguma vez aconteceu (GUMBRECHT, 2010, p. 175)

Segue-se uma bela conclusão nessa direção, talvez excessivamente lírica, como teme o autor, nos exortando - nós, humanos e humanistas - a não perder mais os fugazes momentos de presença que o mundo moderno nos propicia.

Na medida em que esta breve apresentação foi capaz de restituir a proposta do livro, gostaria de deixar fixada a afinidade entre ela e a minha própria, principalmente no "espírito" que informa o livro e na sua ressignificação do conceito de linguagem. Como dissemos, o crítico nos permite pensar em linguagens ${ }^{17}$ de uma maneira ampliada; isto é, enquanto dispersões de objetos que mediam circuitos comunicativos humanos. Estas linguagens não são sistemas harmoniosos de existência ideal, nem se transformam segundo suas próprias leis estruturais. Ainda segundo Gumbrecht, as linguagens fazem parte das coisas do mundo: elas não são o instrumento do monólogo do ser humano que, segundo essa visão, estaria permanentemente apartado do mundo em que, paradoxalmente, ele está inserido. Não existe uma (verdade da) humanidade que esteve sempre - ou pelo menos a partir do seu misterioso surgimento - descolada do mundo. Humanidade essa que recolhida nesse outro mundo da linguagem. Daí a valorização que Gumbrecht faz - mas que não é exclusivamente sua - de Heidegger, pois este último "começou a desenvolver a ideia de um 'desvelamento do Ser' para substituir o conceito metafísico de 'verdade', que aponta para um sentido ou uma ideia", numa tentativa de "devolver a autorreferência humana ao contato com as coisas do mundo" (GUMBRECHT, 2010, p.70).

Gumbrecht nos ajuda a refinar a pergunta inicial feita com Benjamin: que novas experiências a dispersão dos objetos audiovisuais permite? Que subjetividades esta linguagem enseja? Que novas grafias do corpo tornam-se possíveis? Não existe, pelo menos em sociologia, uma resposta em geral para essa questão, separada da historicidade e dos processos históricos que acompanham a emergência deste novo tipo de tecnologia comunicacional. Encorparemos esta resposta com algumas indicações sobre a biografia de Vinicius de Moraes.

\section{O Artístico e o audiovisual: o caso de Vinicius de Moraes.}

Esboçado esse modelo, que se mantém na proposta de Walter Benjamin, mas envolvendo-a com a ideia ampliada de linguagem, tal como a retiramos de Gumbrecht, podemos agora objetivar a situação que nos interessa.

Vamos analisar um curto período da trajetória de Vinicius de Moraes, aquele de seu "chamamento" à música popular - entre 1969 e 
Ausência, composto com Baden Powell; o poeta traja um terno impecável, uma gravata e um cabelo bem partido, apresentando-se como artista de uma maneira que poderia estar em qualquer cerimônia pública de gala, atendendo aos mais altos compromissos de etiqueta e formalidade. Na segunda, quinze anos depois, em um show na Itália, o poeta veste uma camisa de tecido leve, quase translúcido, aberta até abaixo do peito, vários colares e uma pequena fita no pulso; retornando com uma "dancinha" ao palco ao som de Samba pra Vinicius, executada por Toquinho e Miúcha, senta-se em uma mesinha só sua, coberta com uma toalha de estampa de zebra, sobre a qual estão uma garrafa de uísque, um balde de gelo e um copo cheio.

O interesse dessas imagens está, evidentemente, nas mudanças que elas testemunham. Os quinze anos que separam uma e outra são precisamente aqueles em que Vinicius se profissionaliza enquanto músico popular. Seus sucessos enquanto compositor datam já do final dos anos cinquenta, mas, até então, Vinicius não assinava diretamente os seus discos, não realizava shows, e ainda prestava serviços no Itamaraty. O que acontece nesse período de interesse? Ora, Vinicius desenvolve sua personalidade artística em uma direção inédita em sua biografia. Isto não apenas por submeter sua expressão artística a outros critérios de validação e de inserção dentro de um campo, mas ao mudar o suporte dessa expressão. Reencontramos aqui o problema tratado na seção anterior, mas sob uma perspectiva bastante distinta.

Frequentemente, quando elaboramos, nas Ciências Sociais, narrativas a respeito da tecnização dos mundos da vida, da difusão dos 
$18 \mathrm{Na}$ França, por exemplo, é conhecida a figura de Jean Cocteau, poeta e cineasta que, curiosamente, também recriou o mito órfico em uma trilogia de filmes, Le sang d'un poète (1930), Orphée (1950) e Le testament d'Orphée (1960).

19 Em posição muito semelhante posso indicar João Cabral de Melo Neto e Guimarães Rosa, ambos diplomatas contemporâneos de Vinicius, sendo o primeiro seu amigo íntimo, apesar das diferentes concepç̃es poéticas. Adicionando um pouco de profundidade histórica, Bernardo Ricupero assinala este amálgama desde o Romantismo, não apenas no Brasil, mas, guardadas as diferenças, na América Latina como um todo. Referindo-se à condição de escritores como Gonçalves de Magalhães e Araújo Porto Alegre, o autor nos diz: "Não por acaso, boa parte deles tem dupla militância: são políticos ou altos funcionários e escritores"... "Esse fenômeno está longe, porém, de se restringir ao Brasil. No Chile..." (RICUPERO 2004, p. XX-XXI).

${ }^{20} \mathrm{O}$ rádio já estava amplamente popularizado, seus principais "ciclos de exnansão" iá haviam acnntecidก meios audiovisuais, da construção de uma nova sensibilidade associada a uma nova materialidade da comunicação, etc., abstraímos as trajetórias de pessoas singulares em nome de descrições "macro" ou "estruturais" ou, por outra vertente, para "dar vida às coisas". Mas, se se trata realmente de apreender os efeitos das transformações dos meios humanos de inscrição sobre o corpo e o simbólico, isto é, se se trata de pensar que estatutos essas transformações subvertem e que corpos históricos elas criam, como negligenciar trajetórias como a de Vinicius de Moraes?

Proponho aqui pensarmos sua passagem para a música popular sob aspectos complementares: em que medida estes novos suportes audiovisuais, distintos do livro, alteram a relação do artista com seu próprio corpo e como a presença de figuras mediadoras como Vinicius é imprescindível para compreendermos como se estabelece o estatuto artístico dos bens audiovisuais ${ }^{18}$. Tal como foi dito no início deste artigo, não se trata de responder a estas perguntas recorrendo a uma dimensão de transformações abstratas, mas entrelaçando-as com uma dimensão fática que as encarna de uma maneira única.

Ao assinar discos, figurar em capas, escrever textos para contracapas, participar de shows e ter sua imagem enquadrada enquanto um músico popular, o poeta entra em contato com um circuito artístico bastante distinto do campo literário brasileiro ao qual pertenceu durante grande parte de sua vida. Neste último, Vinicius produzia sua poesia em relativo isolamento do contato com o que podemos, grosso modo, chamar de público consumidor de bens culturais. Isso porque a atividade literária nunca respondeu por sua forma de sobrevivência Vinicius era vinculado, vimos, ao Itamaraty, colocando a sua produção artística numa posição ao mesmo tempo livre e subordinada. Livre de certos tipos de demanda do público, subordinada aos parâmetros de validação de um campo literário organizado em torno dessa dependência. Não entraremos aqui em detalhes a respeito dessa questão, mas posso apenas indicar que sua situação material de funcionário do estado não é de forma alguma um caso isolado nas letras brasileiras, consistindo, muito mais, na regra ${ }^{19}$.

Principalmente a partir da segunda metade dos anos 60 Vinicius se envolve com um novo mercado de bens simbólicos, que mobiliza seu corpo de maneira bastante distinta da pertença ao campo literário. É importante ressaltar, também, que o desenvolvimento desse mercado corresponde, neste momento, ao disco, ao cinema e à televisão $^{20}$. E, de fato, Vinicius mantem uma relação íntima não apenas com a música mas, também, e durante muito tempo preferencialmente com o cinema. Durante a primeira metade dos anos de 1950, Vinicius se preparou e esboçou várias tentativas de ser diretor de cinema (FERRAZ, 2013)! Assim como a música, a paixão é antiga. Já em 1930 fez parte do clube de cinéfilos "Chaplin Club", criado por seu amigo Octávio de Faria. Ao longo desta década e dos anos de 1940 atuou como crítico de cinema e, até mesmo, acompanhou as gravações de filmes de Orson Welles, quando esteve nos Estados Unidos entre 1946 e 1950. 
${ }^{21}$ Entrevista "Um analista tentou me pasteurizar", publicada originalmente no Pasquim, em agosto de 1969.

22 Duas de suas composições, "Arrastão" composta com Edu Lobo, e "Valsa do amor que não vem", com Baden Powell, foram premiadas em 1965 no I Festival Nacional de Música Popular Brasileira. A primeira interpretada por Elis Regina, a segunda defendida por Elizeth Cardoso. Na mesma época, foi requisitado para escrever o hino da União Nacional dos Estudantes. O colamento entre Vinicius e o espaço da nascente MPB é máximo neste momento. Sua posição como demiurgo, também. Suas entrevistas são marcadas por esta posição. A segurança e a determinação na hora de atribuir valor a algo ou alguém seja a respeito de música, poesia cinema, política, cultura, sobre si mesmo, etc. - estão na contrapartida dos tipos de pergunta feitas, "O que você acha de...", "Qual sua opinião sobre...", "E o fulano?" (MORAES 2007).

${ }^{23}$ A maioria das perguntas o coloca nesta posição de legislador, ou de quem está fazendo uma síntese da própria história pessoal.
Podemos então retomar o argumento inicial modificando-o: a materialidade dessa indústria em consolidação, bem como a organização e o alcance ampliado do mercado de música popular permitiram - mais que isso, estimularam - uma nova forma de subjetivação artística. Esta nova forma, contudo, existia apenas virtualmente, delineada num horizonte de possibilidades, até ser ocupada por alguém disposto a reconhecê-la e assumi-la. Mas quais as características desta nova posição?

Não há dúvidas de que a passagem de um artista consagrado em outro mundo artístico para esse espaço engendrou, por meio desse gesto mesmo, valor nele. Uma série de entrevistas concedidas por Vinicius no período são instrutivas a respeito dessa transição. Leiamos alguns trechos tendo em mente os dois aspectos trazidos mais acima, e considerando que, tratando-se de entrevistas para grandes veículos de comunicação, interessa mais as categorias que o poeta utiliza para se manifestar que as supostas proposições finais, sempre submetidas a uma economia discursiva por demais contextual.

O que motivou Vinicius a deixar a poesia erudita em direção à música popular? Quando perguntado sobre sua satisfação com o conjunto de sua produção ${ }^{21}$, o poeta esboça uma resposta:

Partir para a canção foi também porque eu não estava satisfeito com o tipo de comunicação que o livro dava, achava estreito e queria ampliar essa comunicação (MORAES, 2007, p.106)
À primeira vista, e de maneira bastante simples, Vinicius parecia buscar uma base mais ampla de apreciadores para sua arte. $\mathrm{O}$ distanciamento temporal da mudança e as consagrações no campo da música ${ }^{22}$ já permitem algumas sínteses de sua trajetória pessoal, marcadas pelas exclusões dos outros possíveis que permaneceram em estado de virtualidade. Logo percebemos que esta mudança não diz respeito apenas a um aspecto quantitativo, ao tamanho de seu público. Vinicius viveu esta mudança como um chamamento.

Atentemos ao detalhe de que Vinicius nomeia o livro como um suporte restrito, e não a poesia versus a canção. Vinicius leva a poesia à canção, pois, na canção, ela pode acontecer como "comunicação emocional simples", algo cada vez mais difícil entre os poetas da sua época. Sobre esse ponto, isto é, o descolamento simbólico entre a poesia e seu suporte escrito, seu meio consagrado, Liliana Harb observa que, contrariando o costume de utilizar o termo "letra", é o termo "poesia" que figura na capa e na ficha técnica do LP inaugural da Bossa Nova, Canção do amor demais (MOLLO, 2010).

Fica bastante claro como esta é uma oportunidade para reelaborar toda a sua trajetória, repensá-la, reescrevê-la, produzir-se como artista. Mais à frente, na mesma entrevista, perguntam-lhe, simplesmente, "o que ele acha da Academia Brasileira de Letras"23. À certa altura de sua resposta, o poeta introduz um tema que seria muito recorrente dali em diante, seu processo de "libertação":

Realmente, eu não tenho nada a ver com a Academia, no sentido que eu não tinha nada a ver 
Neste novo mercado, a supressão de distâncias constitui o valor

com o Itamaraty. Um homem como eu, que leva anos tentando se libertar da gravata, partir para o fardão não tem cabimento. Eu tenho horror a tudo que me oprime e que oprime o ser humano, eu acho que no fundo a gravata é um símbolo da opressão (MORAES, 2007, p.117)

Sua formação erudita vira um parêntese a ser desfeito entre a infância e a fase comunicacional, em que Vinicius faz as pazes com a vida. A mudança é descrita como a realização dos seus impulsos mais íntimos: "eu parti para isso [a música] por uma necessidade pessoal sem nenhuma injunção de fora. Foi, realmente, uma necessidade de digamos assim, arrumar a casa, que é o que eu estou fazendo até hoje" (MORAES, 2007, p.109). O mais interessante, talvez, seja a maneira como o debate canônico a respeito da relação entre arte e vida vai ser transformado, através de um ligeiro deslize, em uma comparação de estilos de relação entre arte e vida. Para Vinicius, existe um determinado estilo de vida artística, uma forma de viver a própria arte, que toma o partido da vida. Esta forma de viver a própria arte não é, de forma alguma, inventada pelo mercado de música popular, mas encontra nele uma possibilidade de objetivação sem precedentes que a leva a desenvolvimentos inéditos, pois o próprio corpo do artista popular passa a fazer parte de sua escritura. Um disco em que Vinicius figura na capa não é apenas a continuação da sua presença por outros meios. É, também, a inscrição daquele meio em seu corpo. Vestir-se, sentar-se, portar-se: toda sua expressão participa do gesto e da produção artística, dentro e fora dos shows. simbólico. Igualmente, tal como aparece em sua fala, arte e vida formam um amálgama inextricável, de direito e, na medida em que a pessoa assume isso, de fato. Não há arte nem vida, há existências humanas que põem, conscientes do risco "de se queimar", estes arcanos mais ou menos em contato. Ainda na mesma entrevista, pede-se, sem mais nem menos, que Vinicius fale de Carlos Drummond de Andrade. Após um breve elogio, o poeta desvia a questão para Manuel Bandeira:

$$
\begin{aligned}
& \text { Eu talvez tivesse uma aproximação maior com } \\
& \text { Bandeira porque acho a obra de Bandeira mais } \\
& \text { redonda, mais perfeita do ponto de vista... digamos } \\
& \text { da vida e da poesia misturadas, não é? Mas acho que } \\
& \text { o Drummond como poeta foi mais longe } \\
& \text { (MORAES, 2007, p.109). }
\end{aligned}
$$

A profundidade dessa sutil reelaboração pode ser vista a partir de outra entrevista. Desde o título extremamente sintético, "A comunicação da poesia que preferiu a vida" ${ }^{24}$, é possível perceber a presença dos mesmos temas, ajuntado o problema da massificação da cultura. A primeira pergunta é contundente: "A comunicação é um valor de sua poesia. Quais os limites que você estabeleceria entre ela e o fenômeno de massificação?" Mas, neste momento, Vinicius não está preocupado com esse limite: "...confesso nada ter a ver com o assunto, mais para um sociólogo"... "A massificação é uma decorrência da sociedade burguesa, do nivelamento da classe média...", "Numa sociedade assim, o ser humano tem cada dia mais necessidade de criar mitos, de 
24 Melhor seria dizer que Vinicius oscila entre estas duas concepções de vida, a banal, do homem comum que cria seus mitos para expiar 0 cotidiano, e a heróica, do poeta que assume a existência fulgurante dos eternamente apaixonados.

${ }^{1}$ Sua declaração evoca, de alguma forma, a máxima oswaldiana de 3 de maio: "Aprendi com meu filho de dez anos/ Que a poesia é a descoberta/ Das coisas que eu nunca vi". Simplificação e comunicação estão expressas na definição redundante de poesia dada nos dois últimos versos. No primeiro, toda a ideia do aprendizado pelo retorno ao préformado, às experiências de menino: à infância. Nesse sentido podemos apontar Vinicius como alguém que leva adiante esta política de memória iniciada pelo modernismo, dando-lhe, contudo, uma abrangência muito maior.

25 Trecho de Samba da Bênção, composta com Baden Powell.

${ }^{26}$ Publicada originalmente no Jornal do Brasil, em 1 de julho de 1971.

${ }^{27}$ Publicada originalmente no Jornal do Brasil, em 1 de julho de 1971.

${ }^{28}$ Neste ano Vinicius escrevia as duas primeiras de suas Cinco Elegias.

${ }^{29}$ Vinte e quatro anos.

${ }^{30}$ Se recuarmos ainda mais no tempo, encontramos o poema Ilha do governador, publicado em seu segundo livro, de 1935: ..."Um dia eu li Alexandre Dumas e esqueci

Dossiê Literatura e Memória

Arquivos do CMD, Volume 3 N.2. Ago/Dez 2015 romantizar a realidade, para escapar à fossa do cotidiano..." "Ora, o poeta é um desses mitos" (MORAES, 2007, p.147).

O poeta, se por um lado leva uma existência extraordinária ao assumir o compromisso de viver a vida com o máximo de intensidade, por outro é mais um mito engendrado pelo cotidiano da vida ${ }^{24}$. Mas assumir assim, de maneira tão despojada, o partido da vida comum, da banalidade, de um veículo de fuga de uma classe esmagada pelo que há de mais maçante na vida moderna, a ponto de contradizer a essência ahistórica do poeta, não foi uma tarefa fácil. Foi preciso despir-se de sua educação formal, dos preconceitos de berço e de classe. Referindo-se à época de publicação dos seus dois primeiros livros, diz:

...nessa época, eu era "inquilino do sublime". E era mesmo, mas artificialmente. Minhas curtições de menino - foram dez anos de férias na Ilha do Governador -, criaram em mim um módulo natural de resistência contra os erros da minha formação, que me permitiram, quando mais adulto, optar por uma simplificação de meu instrumento de trabalho, no sentido de comunicar-se mais e melhor (MORAES, 2007, p.147).

De maneira surpreendente, Vinicius evoca a necessidade de aprender a desaprender os seus preconceitos, os seus erros de formação ${ }^{25}$. Este é o sentido do seu chamamento à música popular. A busca por uma matriz cultural distinta da erudita-burguesa, por uma memória e uma ancoragem simbólica irredutíveis à sua educação clássica, constitui o eixo da reorientação de sua personalidade artística. Não à toa, quando perguntado sobre sua auto-descoberta como "o branco mais preto do Brasil ${ }^{26 ",}$ Vinicius se expressa exatamente da mesma forma; a entrevista se chama, em afinidade com as outras, "Em busca da simplicidade" ${ }^{27}$ :

$$
\begin{aligned}
& \text { Na frase dessa confissão, no Saravah que fiz com o } \\
& \text { Baden, coloquei um problema de classe. Realmente } \\
& \text { nasci numa família de burguesia alta. Para me } \\
& \text { desembaraçar disso tive que sofrer muito, de perder } \\
& \text { os preconceitos, coisas que e ensinaram, tudo } \\
& \text { errado; O meio, até a própria família... Família } \\
& \text { maravilhosa do ponto-de-vista afetivo, mas com } \\
& \text { aquela carga tremenda de preconceitos." } \\
& \text { (MORAES, 2007, p.132). }
\end{aligned}
$$

Desde o primeiro passo no seio da família, seu caminho pelo mundo aponta para essa culminância, para este reencontro consigo que é, também, um reencontro com os homens, despojado dos empecilhos. Trinta e cinco anos separam a declaração acima de uma carta, escrita para sua irmã Leta, em $1937^{28}$, em que Vinicius se expressa em termos incrivelmente semelhantes:

Hoje não consigo mais ser formal. Positivamente não. Tenho impressão que a idade (a idade! ${ }^{29}$ ) me libertou dos últimos preconceitos e conservadorismos que eu tinha. Minha vontade é escrever bem simples e falar mais simples ainda. Pouco e certo. E o essencial, apenas (MORAES 2003 , p.49). ${ }^{30}$

Este longo recuo no passado nos permite imaginar a força do chamamento à que Vinicius respondeu. Entretanto, como dissemos, não é possível explicar a forma efetiva de sua transição para a música 
${ }^{31}$ Publicada originalmente na revista Desfile, em agosto de 1973.

${ }^{32}$ Digo consolidação do seu valor artístico para não incorrer no erro de tomar esta mudança como um gesto cujo único responsável foi Vinicius. Como foi dito acima, ele reconheceu e assumiu uma posição que se delineava no horizonte histórico.

33 Entrevista "Basta de festivais!", inédita (Arquivo casa de Ruy Barbosa). O entrevistador pediu que Vinicius caracterizasse o típico concorrente de festival. O contexto da entrevista parece manifestar a má vontade de Vinicius com o último festival, no qual Tom Jobim foi vaiado.

${ }^{34}$ Em outra gravação, o disco $O$ Poeta e o Violão, em parceria com

Toquinho, a popular apenas por sua individualidade, muito embora a crença do público e de todos a sua volta na sua predestinação para esta "tarefa" esteja na contrapartida do seu próprio sentimento de atender a um chamamento íntimo, e não a qualquer injunção externa. É curioso, nesse sentido, como Vinicius se expressa a respeito da relação com o público e com os Shows. Na entrevista "O apaixonado Vinicius de Moraes"31, quando perguntado sobre a "posição receptiva, quase passiva da mulher" em sua poesia, o poeta, em meio a uma resposta pouco convincente, abre espaço para dizer que

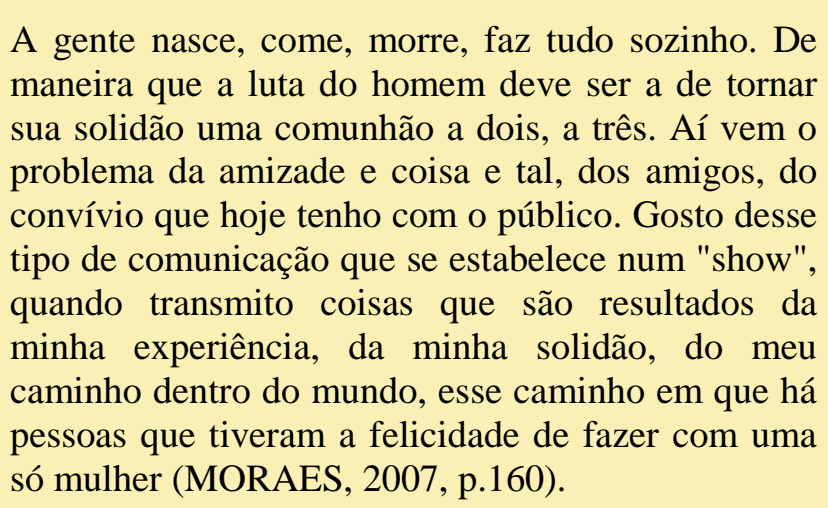

A maneira como se entrelaçam, no seu relato, a estrutura deste espaço que gira em torno de apresentações de pequeno e médio porte - os tais pocket shows que o ocuparam intensamente a partir do final da década de 1960 - , e suas disposições afetivas em um mesmo estado de objetivação - o convívio com o público como um canal para comunicar sua solidão -, deixa claro os pontos acima levantados sobre o papel constitutivo das materialidades da comunicação no desenho de sua personalidade artística. Muito embora a demanda por uma comunicação simplificada esteja presente desde os anos de 1930, a imaginação que a satisfaz não poderia existir ainda.

A partir do material que analisamos, temos uma visão mais abrangente de como a passagem para a música popular repercutiu sobre a vida e a obra de Vinicius, e, em contrapartida, como esta mudança produziu um efeito social sobre o espaço de destino, ao consolidar nele o lastro simbólico da arte popular ${ }^{32}$. Uma última fala sua é interessante para esta conclusão. Observe-se como, aqui ${ }^{33}$, Vinicius fala como alguém que, ao mesmo tempo, observa e participa de uma ampla transformação:

$$
\begin{aligned}
& \text {...justamente agora que um novo e importante } \\
& \text { público - a classe cultivada - se está voltando para a } \\
& \text { música popular por fastio à erudita, começam os } \\
& \text { compositores a elaborá-la demasiado, a entupi-la de } \\
& \text { elementos folclóricos requentados, a estruturá-la } \\
& \text { culturalmente, a despojá-la do elemento que mais a } \\
& \text { torna comunicativa, porque é o de mais difícil } \\
& \text { consecução, que é a simplicidade. Por que não } \\
& \text { seguem eles o exemplo desses três eternos jovens } \\
& \text { que se chamam Heitor Villa-Lobos, Pixinguinha e } \\
& \text { Antônio Carlos Jobim? (MORAES, 2007, p.98) }
\end{aligned}
$$

As três últimas referências, quando ditas por Vinicius, assumem um valor muito evidente: o grande erudito, o grande popular e o grande moderno, que transforma estas duas matrizes em uma só sem descaracterizá-las.

Retornando às nossas imagens iniciais, e à luz da análise biográfica que foi feita, vemos que a distância que as separa é a distância de um aprendizado de novas formas de apresentação artística. 
envolver seu corpo nas imagens. Já a segunda imagem, é A construção de uma imaginação e de uma expressão das emoções que encontra uma contrapartida positivadora na música popular.

Podemos nos perguntar o que mudou nessa apresentação. É notório o despojamento do poeta na segunda cena, em relação à primeira; despojamento expresso em todo o seu corpo e na montagem do ambiente: sentado à mesa com o microfone em uma mão e um copo de uísque na outra, nas anedotas contadas sobre fatos completamente particulares da sua vida, na maneira de "chamar" as músicas ${ }^{35}$. Se lembrarmos que Vinicius, em ambas as gravações, estava diante de um aparelho de gravação e de uma estrutura montada para aquele evento, esses aspectos assumem um caráter de uma estética do despojamento e da informalidade, mas também de uma política da informalidade, na medida em que outros protocolos de conduta são alçados a modelos de expressão.

$\mathrm{Na}$ primeira gravação, também podemos dizer que há uma estética, e uma maneira de apresentar-se específica. Todavia - e agora é necessário fazer uma breve incursão em sua obra -, nesta situação os parâmetros dessa estética são ditados pelo assentimento à uma etiqueta extrínseca - do ponto de vista de sua arte. Se observarmos o desenvolvimento que esta última segue, vemos que desde sua poesia dos anos 40, com Novos Poemas, as Cinco Elegias, e Poemas, Sonetos e Baladas, Vinicius tenta aproximar sua poética do cotidiano da vida. Produzir o cotidiano no que este tem de mais cotidiano, dentro do espaço poético. Sendo assim, podemos comparar a primeira imagem à de um rapsodo, que conjura seu som e seu canto sem, contudo, verdadeiramente a do poeta, ou do dançarino: aquele que é um com o sua expressão. Entre as duas imagens, temos então que a arte de Vinicius passou a incidir no corpo de Moraes $^{36}$.

Para nós, Vinicius proporcionou experiências nas quais não sabemos se estamos fazendo um elogio à arte ou à vida. Em contrapartida, a experiência de sua arte produz um novo olhar sobre a vida. Esta última, no que tem de mais cru ou prosaico, penetra a poesia, mas a poesia também penetra esses espaços da vida.

Todavia, esta realização - do ponto de vista do artista Vinicius não foi possível dentro do campo da poesia. Com sua mudança para a música popular, esta conjunção entre arte e vida assume um significado sociológico: o tipo de experiência da arte inaugurado pela indústria audiovisual, então, em ascensão no Brasil - discos e televisão -, converte o corpo do artista, integralmente, em um bem simbólico ao lado e em relação íntima com sua produção propriamente dita. Nesse sentido, a vida do artista popular não está mais separada de sua arte. Vemos assim que a autoimagem artística de Vinicius encontra uma possibilidade de realização que não existiria de outra forma com a emergência desse novo espaço, que, em contrapartida, Vinicius contribuiu para formar.

\section{Referências Bibliográficas}

ANDRADE, Oswald. Pau Brasil. São Paulo: Editora Globo. $2^{\text {a }}$ Ed. $7^{\text {a }}$ Reimpressão, 2010. 
BENJAMIN, Walter. A obra de arte na era de sua reprodutibilidade técnica. Porto Alegre: LP\&M Editores, 2014.

BOLLOS, Liliana Harb. Canção do Amor Demais: marco da música popular brasileira contemporânea. Per musi, Belo Horizonte, n. 22, p.
83-89,
Dec.
2010.
Disponível
em

$<$ http://www.scielo.br/scielo.php?script=sci_arttext\&pid=S1517-

DERRIDA, Jacques. A voz e o fenômeno. Rio de Janeiro: Jorge Zahar, 1994.

FERRAZ, Eucanaã. Prefácio, em: Jazz \& Co. São Paulo: Companhia das Letras, 2013.

GUMBRECHT, Hans Ulrich. Produção de presença. Rio de Janeiro: Contraponto, 2010.
LIMA, Luiz Costa. Mimesis e Modernidade - formas das sombras. Rio de Janeiro: Graal, 1980.

MORAES, Vinicius de. Encontros. Rio de Janeiro: Beco do Azougue, 2007.

Aguilar, 1980. Poesia completa e prosa. Rio de Janeiro: Nova Querido poeta - correspondência de Vinicius de Moraes. São Paulo: Companhia das Letras, 2003.

RICUPERO, Bernardo. O Romantismo e a ideia de nação no Brasil (1830-1870). São Paulo: Martins Fontes, 2004. 